\title{
Two New Species of the Genus Tisis from Thailand and Notes on Tisis elegans (Insecta: Lepidoptera: Lecithoceridae)
}

\author{
Kyu-Tek Park \\ Center for Insect Systematics, Kangwon National University, \\ Chuncheon, 200-701 Korea \\ E-mail: cispa@kangwon.ac.kr
}

(Received 25 June 2002; Accepted 20 May 2003)

\begin{abstract}
Two new species of the genus Tisis Walker, T. thaiana sp. nov. and T. asterias sp. nov., are described from Thailand. Photos of imagos and illustrations of the male and female genitalia of the new species are provided. Tisis elegans (Snellen, 1903), which was described from Indonesia, is illustrated for the first time with its imago, male genitalia, and some taxonomic notes; a lectotype of the species is designated.
\end{abstract}

Key Words: Description, Oriental region, Tisis thaiana, Tisis asterias

\section{Introduction}

Moths of the genus Tisis are characterized by thickened antennae, with the basal joints of the flagellum concave in the male, but normal in the female; also the first segment of the male labial palpus is relatively long, the 2nd segment has a scaletuft apically, and the 3rd segment is usually concealed in the scales, but is sometimes normal. The genus is restricted to the Oriental Region, with 26 known species (Meyrick 1925; Clarke 1965; Gozmány 1978; Wu 1997, 1998; Park 2001). Only four species of Lecithoceridae, including a species of Tisis ( $T$. helioclina Merick, 1894), had been reported from Thailand until Park (2001, 2002) described a new species of Tisis, T. nielseni Park, 2001, and 15 new species of Torodora. Of the two species of the genus described by Snellen (1903) from Indonesia, Tisis luteella (Snellen, 1903) was redescribed and illustrated by $\mathrm{Wu}$ (1998), and $T$. elegans (Snellen, 1903) is illustrated for the first time in this paper. According to Dr. J. van Nieukerken (pers. comm.), four syntypes of $T$. elegans are deposited in the Department of Entomology, National Museum of Natural History, Leiden, the Netherlands, and Diakonoff previously dissected the genitalia of a male and labeled as "Holotype", but no such designation was published. In order to select a lectotype for T. elegans, photograps of the moth, slide of the male genitalia which Diakonoff had previously prepared, and label data were sent to me by E. J. van Nieukerken of the Museum. Three other syntypes are hereby designated as paralectotypes.

This study was based mostly on the material in the collection of the University of Osaka Prefecture collected by Drs. H. Kuroko, S. Moriuti, T. Saito, Y. Arita, and Y. Yoshiyasu from their lepidopterological expeditions to Thailand in 1983, 1985, and 1987. 
Systematics

Genus Tisis Walker, 1864

Tisis Walker, 1864: 793. Type species: Tisis bicolorella Walker, 1864. Type locality: Sarawak.

Key to species of Tisis in Thailand

1. Forewing oblong, with lead-metallic band medially, lacking pale orange zone preapically

- Forewing somewhat rectangular, lacking such band medially, with pale orange zone preapically T. asterias sp. nov.

2. Median lead-metallic band of forewing broadly expanded toward innner margin, with golden-yellow, L-shaped streak extending to tornus; hindwing in male with row of dense setae along A vein, light brown on upper half and dark brown on lower half. T. thaiana sp. nov.

- Median lead-metallic band of forewing narrow, crescent-shaped, convex, with yellow streak reaching inner margin or without streak; hindwing in male with no row of setae along A vein, almost uniform in colour

3. Median band of forewing curved inwardly toward inner margin; valva of male genitalia with round apex and median cavity semi-ovate T. nielseni

- Median band of forewing curved outwardly toward inner margin; valva of male genitalia relatively narrowed to apex, with median cavity narrowed

T. helioclina

Tisis thaiana sp. nov.

(Figs 1, 3-6)

Diagnosis. The wing pattern is similar to that of $T$. nielseni described from Thailand (Park 2001), but the golden-yellow, L-shaped median band on the forewing is distinctive and reaches near tornus.

Description. Male (Fig. 1). Wingspan 18-18.5 mm. Head golden-yellow dorsally. Tegula dark brown. Thorax dark brown mid-dorsally, golden-yellow laterally. Scape of antenna elongate, dark brown dorsally in distal half, light orange ventrally, broadening towards apex; basal part of flagellum dilated, elliptical, concave dorsally, dark brown, grayish-orange beyond dilated part, dark brown apically. First segment of labial palpus relatively slender, about $1 / 3$ length of 2 nd segment, grayish-orange; 2nd segment grayish orange in basal half, with dark brown, somewhat lead-metallic scaletuft apically; 3rd segment concealed, invisible. Forewing oblong, dark brown at base; costa slightly convex near $1 / 4$ length, thence almost straight; 2-3 golden-yellow transverse streaks before dark-brown fascia; golden-yellow, L-shaped transverse streak arising from 2/5 length of costa and extending to near tornus; other golden-yellow streak along costa beyond midlength, extending to tornus along termen; apex-termen rounded; fringes dark brown; $R_{3}$ and $R_{4}$ stalked near $1 / 3$ length, $R_{5}$ absent; $M_{1}$ approximate at base; $M_{2+3}+C u A_{1}$ coincident, almost parallel with $\mathrm{CuA}_{2}$. Hindwing oblong, but narrowing to apex, brownish gray on upper half and dark brown on lower half, with dense, setae-like scales along $\mathrm{M}_{1}$ and $\mathrm{A}$. 

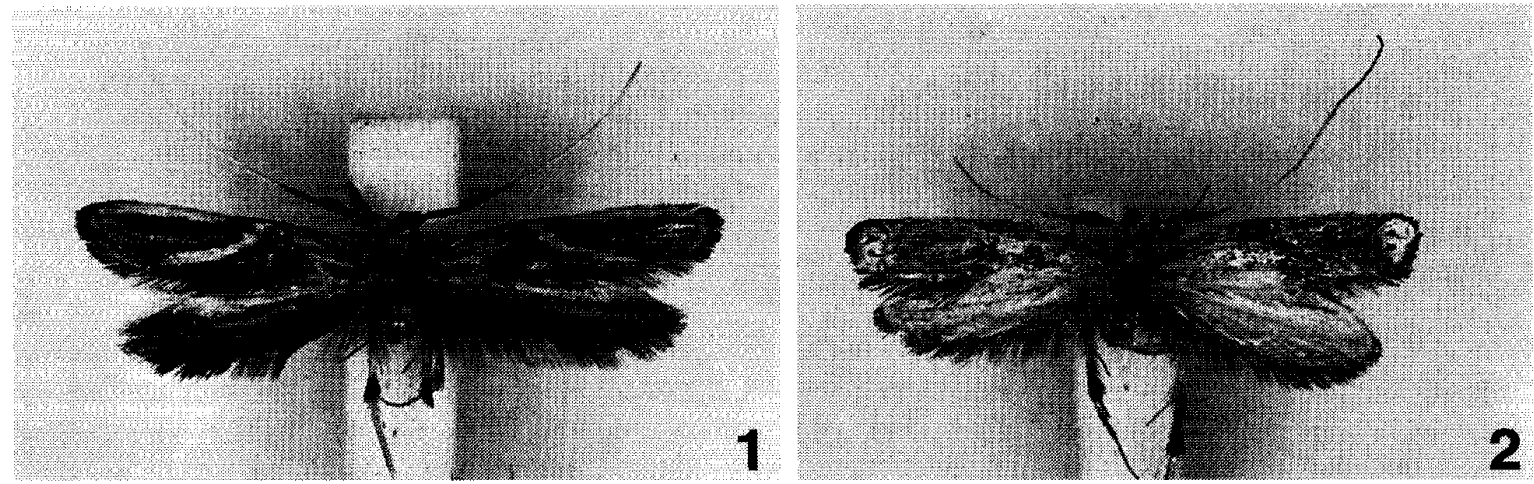

Figs 1-2. Adults. 1, Tisis thaiana sp. nov., male, holotype; 2, T. asterias sp. nov., male, holotype.
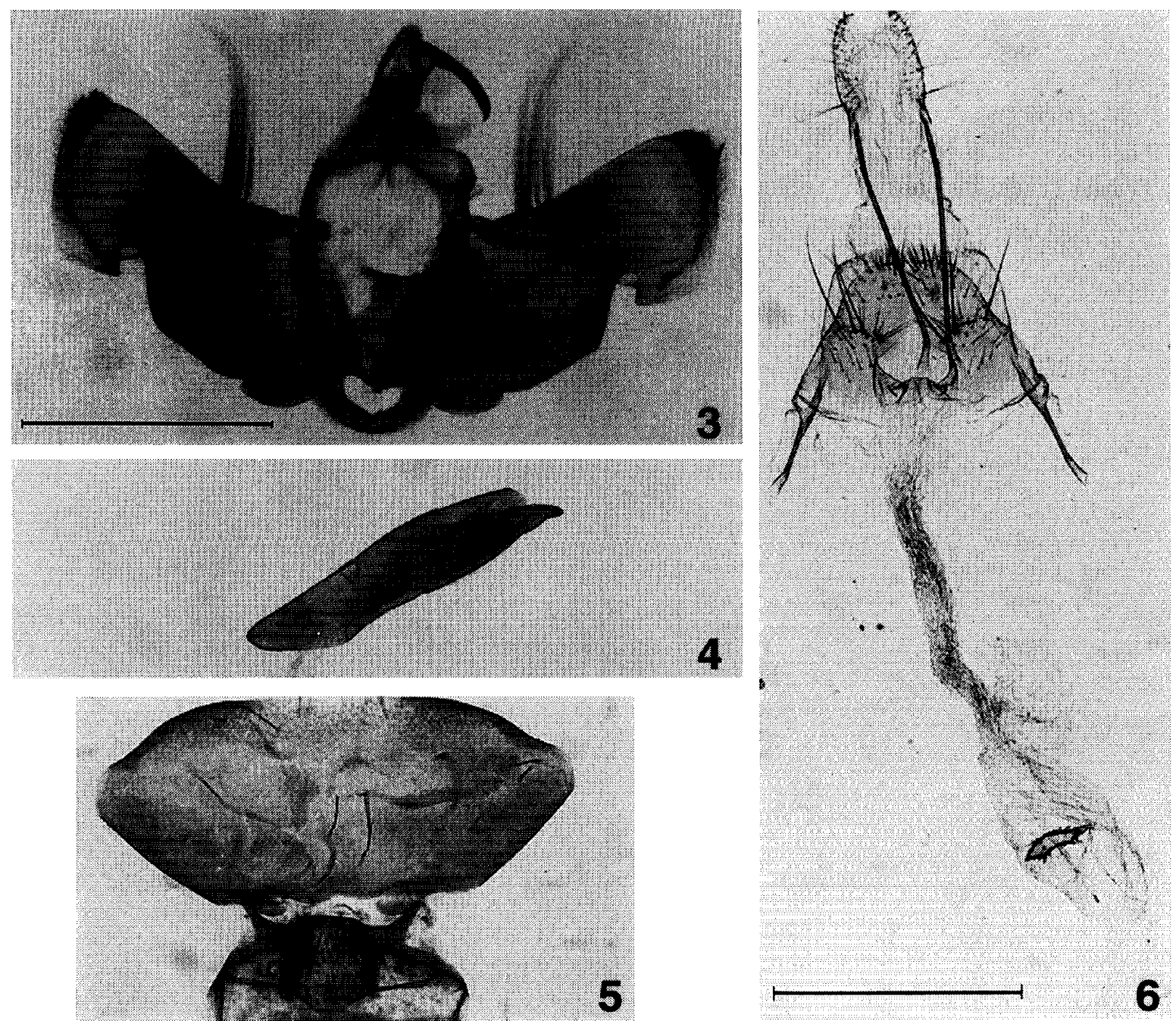

Figs 3-6. Tisis thaiana sp. nov. 3, male genitalia, holotype; 4, aedeagus, holotype; 5 , 8 th sternite, holotype; 6 , female genitalia, paratype. Scales: $1 \mathrm{~mm}$. 
Male genitalia (Figs 3-5). Gnathos relatively long, heavily sclerotized, straight and elongated. Valva relatively broad; costa almost straight, with long, hair-like scales medially; distal part almost quadrate; outer margin slightly convex, with dense bristles along margin beyond apex, and a spine medially; ventral margin with deep emargination beyond middle; median cavity not developed; sacculus very broad, with sharply pointed apex. Juxta almost hexagonal. Aedeagus relatively slender, slightly shorter than valva, almost straight.

Female. Wingspan $16-17.5 \mathrm{~mm}$. Flagellum of antenna dark brown and roughly serrated in basal 1/4, thence pale orange; apical 1/9 dark brown. First segment of labial palpus short; 2nd segment slender, golden-yellow; 3rd segment as long as 2nd, very slender, dark brown. Forewing coloured as in male; venation also similar. Hindwing relatively narrow, grayish-brown throughout, with almost straight costa; apex somewhat acute.

Female genitalia (Fig. 6). Caudal margin of eighth sternite almost straight. Ostium deeply concave, cup-shaped. Antrum membranous. Ductus bursae very long; ductus seminalis arising from conjunction, with corpus bursae. Corpus bursae ovate, relatively small; signum transverally elongate, with short spines along margin and very long one at right corner.

Types. Holotype: male, Thailand, Chanthaburi, Khao Soi Dao, ca. 400 m, 24-25VIII-1987 (coll. Moriuti, Saito, Arita, Yoshiyasu), genitalia preparation no. 4804/ Park. Paratypes: $2 \delta^{\dagger}, 3 q$, same data as holotype, gen. prep. no. 4805/Park ( $q$ ), TS-

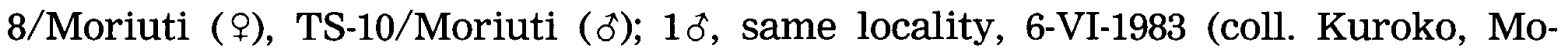
riuti, Arita, Yoshiyasu). Types are deposited in the Entomological Laboratory, University of Osaka Prefecture (UOP), Japan, except for a male paratype in the Center for Insect Systematics, Chunchoen, Korea.

Etymology. This specific name refers to the name of the country.

Tisis asterias sp. nov.

(Figs 2, 7-10)

Diagnosis. This species is superficially very similar to T. luteella, which was described from Java, Indonesia (Snellen 1903), but much smaller in size. Male and female specimens collected from Thailand were compared with specimens of the latter species from Pulo Laut I., SE Borneo [coll. Doherty 1891; No. 870, Walsingham collection 1910-427; genitalia slide prepared by C. Wu, USNM 89258 (male) and 89259 (female), preserved in the National Museum of Natural History, Smithsonian Institution]. This new species can be easily differentiated from the latter by the slender caudal lobes of the juxta, whereas lobes broadly expanded in T. luteella, and lack of an expansion on the ventral margin in the male genitalia, and by the stelliform of the signum in the female genitalia

Description. Male (Fig. 2). Wingspan $17 \mathrm{~mm}$. Head light brown dorsally, pale orange laterocaudally. Tegula dark brown and thorax pale orange. Scape of antenna grayish-brown dorsally, elongate, broadening towards apex; basal part of flagellum dilated, elliptical, concave dorsally, dark brown in basal $2 / 3$. First segment of labial palpus relatively long, about 1/2 length of 2nd segment; 2nd segment with rough scales on inner side and dark-brown scaletuft apically; 3rd segment concealed in scales of 2nd. Forewing relatively broad; costa convex near 1/4 length; 


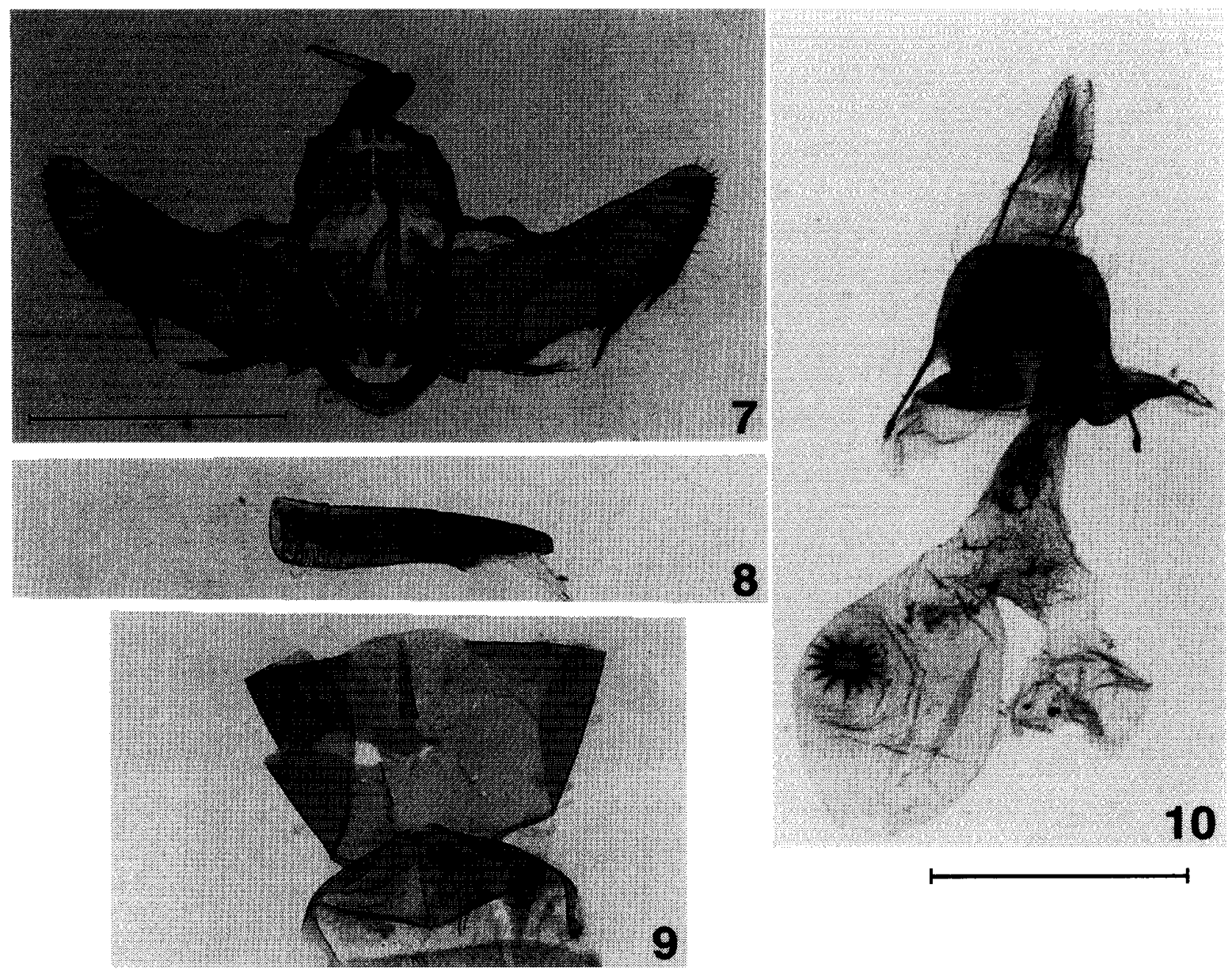

Figs 7-10. Tisis asterias sp. nov. 7, male genitalia, holotype; 8, aedeagus, holotype; 9 , 8th sternite, holotype; 10, female genitalia, paratype. Scales: $1 \mathrm{~mm}$.

ground color brownish-orange, speckled with dark brown scales throughout; large, pale orange semi-ovate zone well presented preapically, bordered by grayishbrown scales anteriorly, with two or three dark brown spots on inner side; termen slightly oblique; fringes dark brown, relatively short on termen, longer on inner margin; $R_{3}$ and $R_{4}$ stalked beyond 3/4 length, $R_{5}$ absent; $M_{1}$ approximate at base; $\mathrm{M}_{2+3}+\mathrm{CuA}_{1}$ coincident, almost parallel with $\mathrm{CuA}_{2}$. Hindwing oblong, with rounded apex; $\mathrm{M}_{2+3}$ and $\mathrm{CuA}_{1}$ stalked beyond midlength.

Male genitalia (Figs 7-9). Gnathos heavily sclerotized, almost straight beyond basal $1 / 3$, bent preapically. Valva with costal margin nearly straight; costal bar (i.e., bridge-like structure connecting tegumen and costa) well developed; outer margin slightly convex, strongly oblique, with dense, relatively long bristles along margin; semi-ovate cavity well developed, with cresent-shaped upper margin medially; ventral margin with small protrusion near base, followed by emargination; sacculus narrow, extending to half length of semi-ovate cavity. Caudal lobes of juxta rod-shaped, asymmetrical, with right one longer. Aedeagus shorter than valva, about $2 / 3$ length of latter, broadening towards apex, almost straight.

Female. Wingspan $15 \mathrm{~mm}$. Antenna dark brown in basal $1 / 4$ and apical $1 / 5$, pale orange between them. Second segment of labial palpus slender, grayish- 
orange, 3rd segment shorter than 2nd. Forewing coloured as in male; venation also similar. Hindwing much narrower, with almost straight costa; apex somewhat acute.

Female genitalia (Fig. 10). Caudal margin of eighth sternite almost straight. Antrum heavily sclerotized. Ductus bursae short; ductus seminalis wider than ductus bursae, arising from middle of ductus bursae. Corpus bursae ovate, relatively large; signum round, stelliform, with 15 strong spines along margin.

Types. Holotype: male, Thailand, Rhanong, Na Kha, ca. 250 m, 15-X-1985 (coll. Kuroko, Moriuti, Saito, Arita), genitalia preparation no. TS-5/Moriuti. Paratype: 1 , same data as holotype, gen. prep. no. TS-9/Moriuti. Types are deposited in the UOP, Japan, on an indefinite loan from Thailand.

Etymology. The specific name is derived from Latin, "aster" (= star), referring to the shape of the signum.

Tisis elegans (Snellen, 1903)

(Figs 11-14)

Cacogamia elegans Snellen, 1903: 50. Type locality: Java, Indonesia. Lectotype designated herein.

Tisis elegans: Meyrick 1925: 204; Wu 1998: 192.

Diagnosis. Wingspan $17-19 \mathrm{~mm}$. This species can be easily distinguished from its allies by the widely expanded golden yellow zone extending beyond the median band. This species is superficially similar to T. argyrophaea Meyrick, 1910 which was described from Kuching, Sarawak, but can be distinguished from the latter by the narrow forewing, the costa convex beyond middle, and the shape of the caudal lobes of the juxta in the male genitalia.

Material examined. 1 $\delta$, W. Java, 1885, genitalia preparation no. 8117/Diakonoff. The genitalia of this specimen was dissected by Diakonoff, and its slide is labeled as "Holotype", but no such designation was published. Here I designate this specimen as the lectotype of the species and three other syntypes are designated as paralectotypes.

Remarks. Since this species was described from W. Java (Preanger 1500-1600 $\mathrm{m}$, Sythoff) by Snellen (1903), no further taxonomic study has been made and no illustrations of the adult or of the genitalia of the type specimens have been published. In the original description of the species, the number of the types was not indicated. Dr. E. J. van Nieukerken informed me that there are four syntypes of this species, three males and one female, all labeled similarly, in the National Museum of Natural History, Leiden. Among them, only a male was dissected by Diakonoff as mentioned above. It is needed to designate a lectotype and paralectotypes from these syntypes to avoid further confusions for taxonomic works of this group.

Distribution. Java, Indonesia. 




Figs 11-14. Lectotype specimen of Tisis elegans (Snellen, 1903). 11, adult; 12, labels; 13, male genitalia; 14, genital preparation. (C) The National Museum of Natural History, Leiden, used with permission.

\section{Acknowledgments}

I am indebted to Dr. T. Hirowatari, Entomological Laboratory, the University of Osaka Prefecture, Sakai, Japan, and Dr. J. Brown, Department of Systematic Biology, National Museum of Natural History, Smithsonian Institution, Washington D.C., USA, for their assistance in loaning specimens. Also, my sincere appreciation is offered to Dr. E. J. van Nieukerken, Department of Entomology, National Museum of Natural History, Leiden, the Netherlands, for his kindness in sending me photographs of the type specimen and other information regarding T. elegans.

\section{References}

Clarke, J. F. G. 1965. Catalogue of the Type Specimens of Microlepidoptera in the British Museum (Natural History) Described by Edward Meyrick. Vol. 5. The British Museum, London, $255 \mathrm{pp}$.

Gozmány, L. 1978. Lecithoceridae. In: Amsel, H. G., Gregor, F. and Reisser, H. (Eds) Microlepidoptera Palaearctica. Vol. 5. Verlag Georg Fromme, Wien, 306 pp.

Meyrick, E. 1925. Lepidoptera Heterocera. Family Gelechiidae. Genera Insectorum 184: 1-290, pls. $1-5$.

Snellen, P. C. T. 1903. Beschrijvingen van nieuwe exotische Tortricinen, Tineinen, en Pterophorinen, benevens aanteekeningen over reeds bekend gemaakte Soorten. Tijd- 
schrift voor Entomolgie 46: 43-52.

Park, K. T. 2001. A new species of the genus Tisis (Lepidoptera, Lecithoceridae) from Thailand. Korean Journal of the Systematic Zoology 17: 59-63.

Park, K. T. 2002. Genus Torodora Meyrick in Thailand, with descriptions of fifteen new species. Insecta Koreana 20: 147-166.

Walker, F. 1864. Genus Tisis. List of the specimens of lepidopterous insects in the collection of the British Museum (29): 793.

Wu, C. 1997. Lepidoptera Lecithoceridae. Fauna Sinica, Insecta, Vol. 7. Science Press, Beijing, $302 \mathrm{pp}$.

Wu, C. 1998. Genus Tisis Walker from Malaysia and Indonesia (Lepidoptera, Lecithoceridae), with description of three new species. Zoological Studies 37: 191-196. 